University of Nebraska - Lincoln

DigitalCommons@University of Nebraska - Lincoln

\title{
The co-emergence of cognition, language, and speech motor control in early development: A longitudinal correlation study
}

Ignatius S. B. Nip

San Diego State University, inip@mail.sdsu.edu

Jordan R. Green

University of Nebraska-Lincoln, jgreen4@unl.edu

David Marx

University of Nebraska - Lincoln, david.marx@unl.edu

Follow this and additional works at: https://digitalcommons.unl.edu/specedfacpub

Part of the Special Education and Teaching Commons

Nip, Ignatius S. B.; Green, Jordan R.; and Marx, David, "The co-emergence of cognition, language, and speech motor control in early development: A longitudinal correlation study" (2011). Special Education and Communication Disorders Faculty Publications. 69.

https://digitalcommons.unl.edu/specedfacpub/69

This Article is brought to you for free and open access by the Department of Special Education and Communication Disorders at DigitalCommons@University of Nebraska - Lincoln. It has been accepted for inclusion in Special Education and Communication Disorders Faculty Publications by an authorized administrator of DigitalCommons@University of Nebraska - Lincoln. 
Published in Journal of Communication Disorders 44:2 (March-April 2011), pp. 149-160;

doi: 10.1016/j.jcomdis.2010.08.002 Copyright (C) 2010 Elsevier Inc. Used by permission.

Submitted January 1, 2010; revised July 31, 2010; accepted August 26, 2010; published online September 17, 2010.

\title{
The co-emergence of cognition, language, and speech motor control in early development: A longitudinal correlation study
}

\author{
Ignatius S.B. Nip, ${ }^{1}$ Jordan R. Green, ${ }^{2}$ and David B. Marx ${ }^{3}$ \\ 1. School of Speech, Language, and Hearing Sciences, San Diego State University, \\ 5500 Campanile Dr., San Diego, CA 92182-1518, USA \\ 2. Department of Special Education \& Communication Disorders, \\ University of Nebraska-Lincoln, Lincoln, NE, USA \\ 3. Department of Statistics, University of Nebraska-Lincoln, Lincoln, NE, USA \\ Corresponding author - I. S. B. Nip, tel 619 594-2421, fax 619 594-7109, email inip@mail.sdsu.edu
}

\begin{abstract}
Although the development of spoken language is dependent on the emergence of cognitive, language, and speech motor skills, knowledge about how these domains interact during the early stages of communication development is currently limited. This exploratory investigation examines the strength of associations between longitudinal changes in articulatory kinematics and development of skills in multiple domains thought to support early communication development. Twentyfour children were investigated every 3 months between the ages of 9 and 21 months. Movements of the upper lip, lower lip, and jaw were transduced using a three-dimensional motion capture system to obtain age-related changes in movement speed and range of movement. Standardized measures of cognition and language from the Battelle Developmental Inventory, 2nd edition and the MacArthur-Bates Communicative Development Inventory were also collected. Significant associations were identified between orofacial kinematic and the standardized measures of language and cognitive skills, even when age served as covariate.

These findings provide preliminary evidence of interactions between cognition, language, and speech motor skills during early communication development. Further work is needed to identify and quantify causal relations among these co-emerging skills.

Learning outcomes: The reader will be able to: (1) describe how cognition, language, and speech motor control may interact during speech development, (2) describe the associations between speech kinematic characteristics and measures of cognition and language.
\end{abstract}

\section{Introduction}

Complex social behaviors, like spoken language, are the product of multiple processes including those related to motor, cognitive, and linguistic processes (Levelt, 1989; Smith and Goffman, 2004; Thelen, 2001). These processes co-emerge and interact as children progress through various phases of development. Although investigating these interactions poses immense research challenges, such information is essential for a comprehensive understanding of the many factors that contribute to developmental speech impairments. The current study is motivated, in part, by several findings from investigations demonstrating bidirectional interactions among different domains of knowledge and performance (i.e., speech motor control, phonology, language and affect) during early communication development. Our working hypothesis is that gains in oral motor control, specifically increased articulatory speed, coincide with gains in gestural communication, and other cognitive and linguistic skills. Our rationale for 
this hypothesis is that newly emerging cognitive and linguistic skills are associated with continued articulatory refinement (Green \& Nip, 2010). A better understanding of how cognition, language, and speech motor control interact may help to inform theoretical models of speech development and impact early speech intervention.

\subsection{The co-emergence of symbolic and motor systems: gestures and symbolic play}

The co-emergence of symbolic and motor systems in young children is most lucidly demonstrated in the literature on the development of gestures. Like speech, gestures and play skills involve motor skills that are dependent on the interaction of motor, cognition, and language processes. Prior research has shown that these behaviors are correlated with language and cognitive skills at various points in early development. At approximately 9 months of age, the use of deictic (e.g., pointing, giving) gestures is positively associated with receptive vocabulary skills (Thal \& Tobias, 1992). Additionally, the use of gestures to label objects is correlated with the rate of expressive vocabulary acquisition (Acredolo \& Goodwyn, 1988). Similarly, advanced play skills are associated with advanced language skills. Using and moving objects in a functional and appropriate in play at 13 months of age are associated with standardized language scores at 22 months of age (Ungerer \& Sigman, 1984). The simultaneous production of one-word utterances and gesture predicts the emergence of two-word utterances approximately two and a half months later (Iverson, Capirci, Volterra, \& Goldin-Meadow, 2008). The McCune-Nicolich references have now been deleted from the reference list. The combined use of gesture with speech is associated with the transition from one-word to two-word utterances (Goldin-Meadow and Butcher, 2003; Özçaliskan and Goldin-Meadow, 2005).

One possible explanation for the correlation between gestures and language at specific periods of development is their reliance on shared underlying processes (Thal, 1991; Thal and Tobias, 1994) such as information processing skills or working memory (Thal, 1991). For example, researchers have proposed that the ability to relate two separate actions is an essential skill for both sequencing actions in play and combining words during verbal communication (Fenson \& Ramsay, 1980). Developmental gains in a cognitive process may be similarly associated with simultaneous gains in language and speech motor skills.

\subsection{Language and non-symbolic motor acts}

These prior investigations on early gestures and symbolic play demonstrate developmental interactions among skills in multiple domains including language, cognition, and symbolic motor acts. Additional evidence of acrossdomain links in early development comes from studies on the co-morbidity of impairments in language and motor function (i.e., non-symbolic motor performance). Children with specific language impairments have been shown to have fine and gross motor skill deficits. For example, children with delayed language have been shown to have difficulty with hopping (Stark \& Tallal, 1981) and balance (Powell \& Bishop, 1992). Children with language impairments also have more difficulty performing nonspeech oral motor tasks (Alcock, 2006; Stark and Blackwell, 1997), suggesting that these oral motor skills may be one of many skills needed for later language development (Alcock, 2006).

\subsection{Language and speech sound acquisition}

Developmental dependences between speech motor control and language ability may, in part, account for the comorbidity between expressive language and speech disorders. In comparison to their typically-developing peers, children with expressive language delay tend to have delayed articulatory development (Whitehurst, Smith, Fischel, Arnold, \& Lonigan, 1991), more variable lip and jaw movements during speech (Goffman, 1999), restricted consonantal inventory, limited syllable shapes (Carson et al., 2003; Paul and Jennings, 1992; Rescorla and Ratner, 1996; Williams and Elbert, 2003), and limited phonological skills (Williams \& Elbert, 2003). In addition, young children with impoverished phonetic repertoires tend also to have limited vocabularies (Stoel-Gammon, 1991). Conversely, children who acquire words at earlier ages tend to have larger vocabulary size and phonetic inventory at 24 months than do children who acquire words later (Stoel-Gammon, 1991). In comparison to age-matched peers, 2 -year-olds with advanced lexicon sizes have fewer articulation errors, cluster reductions, and final consonant deletions (Smith, McGregor, \& Demille, 2006).

In addition, children's early vocalizations patterns have been shown to predict their later developing language skills. The number of different syllables during babbling and a preference for consonant use are positively correlated with language scores 5 months later for toddlers with expressive language delay (Whitehurst et al., 1991). Children with a higher number of vocalizations containing consonants at 9 months of age had advanced phonology at the age of 3 years compared to children who had fewer consonants at 9 months (Vihman \& Greenlee, 1987).

\subsection{Speech kinematics, language, and cognition}

Although the relevant literature on speech motor development is sparse, several findings support the suggestions that the development of speech motor control may be spurred by increasing demands imposed by emerging phonologic, linguistic, and cognitive abilities. For example, prominent changes in lip and jaw movements have been 
observed at 2 years of age, which is typically the age at which children acquire new sounds into their phonological systems and experience an exponential growth in vocabulary. Specifically, to produce oral closure during bilabial consonants, 2-year-old children shift from an articulatory strategy that primarily relies on jaw movement to one that includes a contribution from the lips (Green, Moore, Higashikawa, \& Steeve, 2000). During this transition, the children also exhibited a transient increase in the variability of jaw movement patterns (Green, Moore, \& Reilly, 2002). Green et al. (2002) speculated that the transient spike in variability was spurred by growing demands on the speech motor system imposed by emerging linguistic and cognitive abilities.

Studies demonstrating shifts in articulatory control in response to experimentally controlled levels of speaking task difficulty provide additional evidence of interactions between the speech motor system and other domains. For example, studies on adult articulatory performance have demonstrated that speech performance variability decreases as tasks become less syntactically complex (Kleinow and Smith, 2006; Walsh and Smith, 2002) and cognitively demanding (Dromey \& Bates, 2005). Variability in lip and jaw movement patterns have similarly been shown to decrease with age (Goffman and Smith, 1999; Smith and Zelaznik, 2004). Thus, developmental gains in cognitive and linguistic processing may have a stabilizing effect on articulatory movements with age.

Research has also shown that in adults and children the speed of articulator movements increase as speaking tasks become more linguistically and cognitively demanding (Nip \& Green, 2006). When interpreted with respect to the developing child, these findings suggest that articulatory movements will become faster, particularly during the first 2 years of life when children are rapidly acquiring new language and cognitive skills. Indeed, the effects of task on articulatory speed may underlie some of age-related gains in articulatory speed that have been reported previously (Goffman and Smith, 1999; Smith and Gartenburg, 1984; Smith and Zelaznik, 2004).

\subsection{Purpose}

The primary goal of this study is to determine the association between orofacial kinematic variables, such as movement speed and range of movement, and standardized measures of cognitive and language development during the early stages of communication development. This exploratory study is intended to provide future directions for studies addressing the interactions among multiple developmental domains during early speech development in typically-developing and speech-delayed children.

\section{Methods}

\subsection{Participants}

Participants were children from monolingual English-speaking families in the Midwest. The families were recruited for a larger longitudinal study through flyers posted in pediatrician offices and newspaper ads. The children were reported by parents to be born at term with no neurological, vision, hearing, or physical impairment. A total of 30 participants were recruited, however six participants did not complete the current study because the family moved (1 participant), were later diagnosed with developmental or speech delays (2 participants), or the families elected to end their involvement with the study (3 participants). A total of 24 children (11 males, 13 females) were studied every 3 months from 9 to 21 months of age for the current investigation.

\subsection{Procedure}

Each child was seen for two sessions at each age level. At the first session, a speech-language pathologist administered the Battelle Developmental Inventories, 2nd edition (Newborg, 2005). The BDI-2 is a developmental test that includes subtests in receptive and expressive communication skills, gross and fine motor skills, and cognitive subtests. Parents were also asked to complete the MacArthur Communicative Developmental Inventories (Fenson et al., 1993). Hearing was screened using the AuDX (Biologic Systems, Ltd.), which tests otoacoustic emissions at 2, $3,4,5 \mathrm{kHz}$. On occasional data points, some children did not pass the hearing screening. Typically, this was the result of the child being fussy, vocalizing, or congested, situations in which reliable otoacoustic emission results cannot be obtained. We used the criteria that two consecutive "refer" readings would eliminate the child from the study; however, this did not occur with any of the participants.

Orofacial behaviors were captured using an eight-camera optical motion capture system (Motion Analysis, Ltd.) in a follow-up session approximately a week before or after the developmental screening. Fifteen reflective markers were placed on each child face. Two markers were placed above each eyebrow. One marker was placed on the bridge of the nose and one on the nose tip. One marker was placed on the upper lip on the vermillion border, and one on the lower lip, directly below the upper lip marker. Markers were also placed at the corners of the mouth, at the oral commissure. Three markers were placed on the jaw. One was placed at the center (mental protruberance) and one on each side a couple of centimeters to the left and right of the central jaw marker. Four markers were placed on a rigid head marker, which also housed a microphone that was used to record vocalizations and speech. The head marker was placed on the central forehead, with the top of the marker at the hairline. This head marker was later used to subtract head movement from the other markers during data analysis (Figure 1).

Kinematic data of the orofacial behaviors were captured at 120 frames per second. Audio was captured at $44.1 \mathrm{kHz}, 16$ bits. High-resolution digital video was also captured to assist in data parsing. 


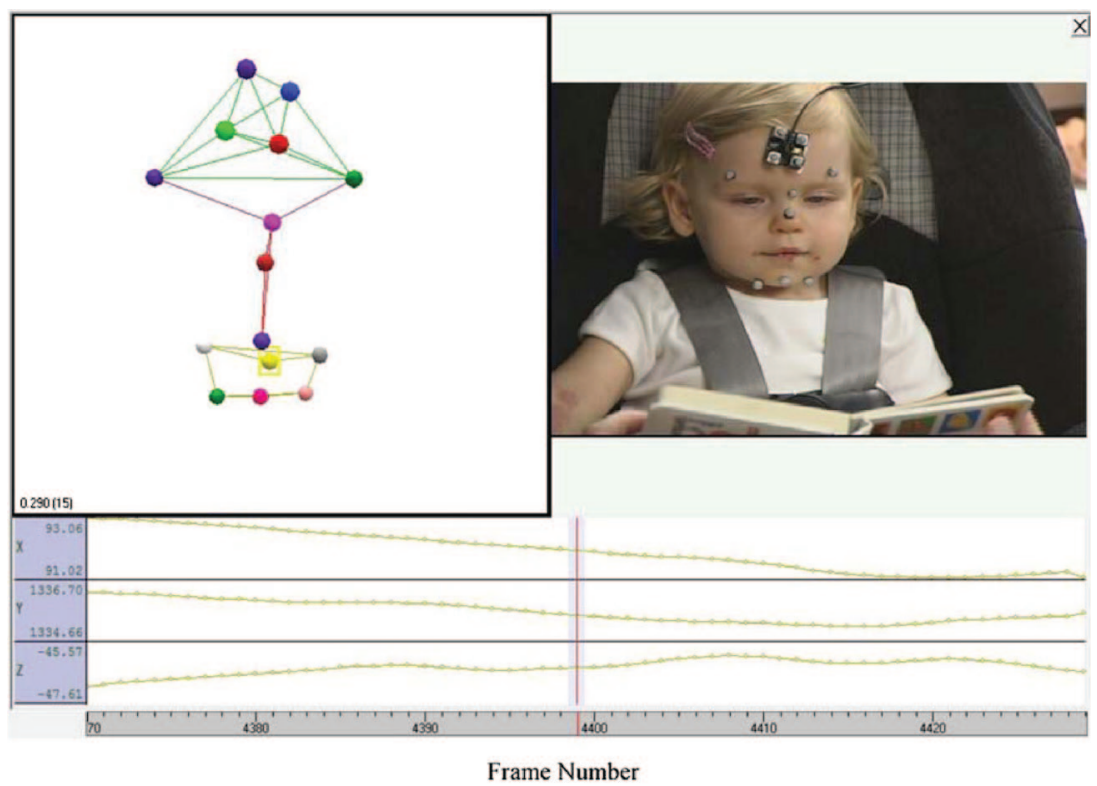

Figure 1. Marker placements used to record upper lip, lower lip, and jaw movements (right pane), three-dimensional model of the markers (left pane), and movement trace of the lower lip (bottom pane). Originally published in Nip et al. (2009).

Children sat in a car seat that was secured to a chair. Each child's primary caregiver, usually the mother, sat in front of the child. To sample orofacial movement during a wide variety of communication contexts, each data collection session consisted of several different conditions. At the beginning of each session, spontaneous interactions were captured between the child and parent. The parents were asked at that time to play with their child while the motion system was being calibrated. After a few minutes passed, the caregiver was given a set of toys and asked to take a few turns with the toy and then pause and wait to see what the child would do ("play" condition).

Three different sets of toys were eventually provided for each parent-child dyad. One set of toys were designed to elicit requesting, including toys in transparent containers, and toys with multiple parts (e.g., Mr. Potatohead with various body parts). The second set of toys was designed to elicit joint attention. These toys included picture books, and "surprise" bags (bags with various toys inside). The last set of toys encouraged social interaction. Toys in this set included pretend food, dolls, and pretend tools. On average, each bin of toys was used for approximately 4-5 min before being replaced by another. The length of each testing and motion capture session typically lasted up to $45 \mathrm{~min}$, depending on the child's mood.

\subsection{Data parsing and transcription}

Trained laboratory assistants identified all speech movements within each motion capture session, using the digital video recording to guide their transcriptions. Speech movements were defined as orofacial movements that were accompanied by vocalizations. Movements were considered separate epochs if the transcriber did not observe movement on the video for $500 \mathrm{~ms}$ or longer. The final data corpus included spontaneous movements and vocalizations such as babbles, words, and phrases. Each speech movement was parsed into a separate file and the markers were then labeled (e.g., lower lip, upper lip, etc.). All movement traces were then low-passed filtered $\left(F_{\mathrm{LP}}=10 \mathrm{~Hz}\right)$.

\subsection{Measures}

\subsubsection{Cognitive, language, motor, self-care skills development}

The Battelle Developmental Inventories, 2nd Edition (BDI-2, Newborg, 2005), a norm-referenced assessment battery of developmental skills was given to assess general development of all the children at each age. The BDI-2 examines skills in personal-social, communication, motor, cognitive and adaptive (ability to integrate skills in the other four domains for daily-living skills) domains. The age-equivalent scores from the receptive communication, expressive communication, attention and memory, and perception and concepts subtests were included in the analyses.

\subsubsection{Vocabulary}

The MacArthur Communicative Developmental Inventories (CDI, Fenson et al., 1993) was used to obtain detailed information regarding each child's receptive and expressive vocabulary and early communicative gesture competence. This test is a norm-referenced parent report that examines receptive and expressive vocabulary in children from 9 to 15 months using the Words and Gestures form and 16-30 months of age using the Words and Sentences 

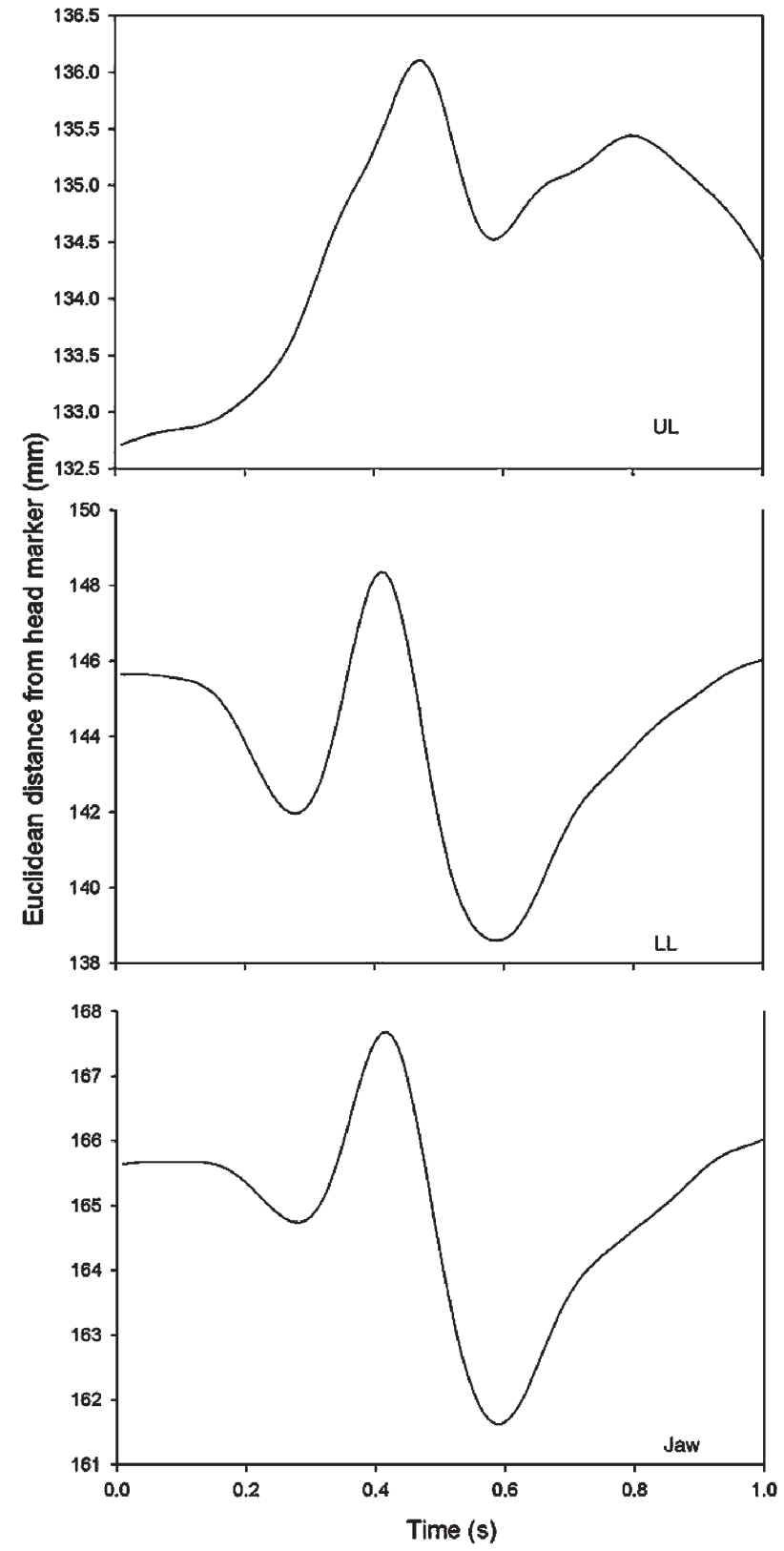

Figure 2. Example of upper lip (top panel), lower lip (middle panel), and jaw (bottom panel) of a 21 month-old saying the word "grape." Euclidean distance $(\mathrm{mm})$ from the head marker is on the vertical axis with time (s) on horizontal axis. Originally published in Nip et al. (2009).

form. This assessment provided information on words understood, phrases understood, total gestures produced from the Words and Gestures form, and words produced from both forms.

Because each participant was seen at 9, 12, 15, 18, and 21 months of age, data was collected using the Words and Gestures form at the ages of 9, 12, and 15 months and then the Words and Sentences form at the ages of 18 and 21 months. Scores were only obtained up to 15 months for the following measures, which were only on the Words and Gestures form not on the Words and Sentences form: the number of phrases understood, the number of words understood, and the total number of gestures produced. Consequently, only the number of words, which was on both forms, was reported from 9 to 21 months.

\subsubsection{Quantitative analyses of the three-dimensional kinematic traces}

Custom MATLAB (Mathworks, Ltd.) algorithms were used to obtain movement characteristics of a given utterance. To obtain facial movements that were independent from those of the head, the movement of the lips and jaw were expressed as the 3D Euclidean distance from the right top head marker. Movement of the lower lip marker resulted from the net movement of the lower lip and jaw. Jaw movement was obtained from the markers that were left or right of the center of the jaw in order to minimize error in fleshpoint tracking of the mandible (Green, Wilson, Wang, \& Moore, 2007). Periods at the beginning and end of each epoch with no movement in all three mark- 
ers (lower lip, upper lip, and jaw) were discarded before obtaining specific kinematic measures. For each epoch and marker, the peak opening and closing speeds $(\mathrm{mm} / \mathrm{s})$ were recorded. The range of movement $(\mathrm{mm})$ for each marker, as determined between the distance between the maximum and minimum position of the marker from the head marker for a given movement epoch, was also obtained and represented how much a child moved an articulator during the epoch. The range of movement of a epoch was used as a proxy for movement space, which has been shown to change over the first year of life (Green \& Wilson, 2006).

Peak speed of lip and jaw movement was used as an indicator of speech motor development in this study because prior research has shown that speed increases across development (Goffman and Smith, 1999; Smith and Gartenburg, 1984; Smith and Zelaznik, 2004) and because it can easily be derived from a wide variety of utterances (Figure 2).

\subsection{Statistical analyses}

To screen for outliers, the values for each kinematic variable (e.g., closing speed) across all sessions were examined to determine if the observations fell within the normal distribution. Least-square means were calculated by age and orofacial behavior. Residuals were taken for each observation. The residuals were then fit in a normal curve and observations that fell outside of the normal curve were removed. A total of 41 observations out of 8872 movement epochs were removed using this procedure. The means of each session for each participant were then calculated.

The mean opening and closing speeds and ranges of movement were taken for the upper lip, lower lip, and jaw markers for each participant at each age level. The scores from the BDI-2 and the CDI were correlated with each kinematic measure. Because the data were collected longitudinally over a year, partial correlations controlling all variables for age were also conducted. Previous studies (Smith \& Zelaznik, 2004) have indicated that articulatory movement speeds increase with age. Similarly, the scores from the standardized tests would also be expected to increase with age. If correlations between the two sets of variable were found, overall maturation could be the causal variable. Partial correlations would help to determine if age might be a "third variable" or the underlying reason for significant correlations between standardized test scores and the kinematic measures. We hypothesized that there will be some significant positive, partial correlations between kinematic characteristics of speech, specifically speed and range of movement, and language and cognition scores.

\section{Results}

Table 1 presents the means and standard errors for the mean of opening and closing speeds and range of motions for the jaw, lower lip, and upper lip markers at each age level. Table 2 presents the means and standard deviations of the age-equivalent scores for the receptive communication, expressive communication, attention and memory, and perception and concept subtests of the BDI-2 as well as the number of phrases understood, number of words understood, number of words produced, and the number of gestures produced of the CDI. Table 3 presents the correlation of sex with each of the kinematic variables. Overall, the female children had faster speeds and range of movements than the male children.

\subsection{BDI-2 scores}

Table 4 presents the correlation between each kinematic variable and sex and the age equivalent scores for the receptive communication, expressive communication, attention and memory, and perception and concepts subtests of the BDI-2.

The receptive communication subtest positively correlated with many of the kinematic variables for the jaw, lower lip, and upper lip. The age-equivalent score for receptive communication correlated with the opening speed

Table 1. Means and standard errors of the mean for the closing and opening speeds and ranges of movements for the upper lip, lower lip, and jaw at each age level.

\begin{tabular}{|c|c|c|c|c|c|}
\hline & \multicolumn{5}{|l|}{ Age } \\
\hline & 9 months & 12 months & 15 months & 18 months & 21 months \\
\hline \multicolumn{6}{|l|}{ Jaw } \\
\hline$N$ & 21 & 22 & 18 & 22 & 17 \\
\hline Cl. Speed & $28.66(1.63)$ & $32.59(2.65)$ & $41.05(3.92)$ & $39.02(2.58)$ & $40.07(2.81)$ \\
\hline Op. Speed & $25.46(1.14)$ & $29.90(3.17)$ & $36.64(4.39)$ & $34.85(2.66)$ & $36.41(2.25)$ \\
\hline R.O.M. & $5.99(.38)$ & $5.87(.45)$ & $6.64(.58)$ & $6.20(.34)$ & $6.47(.35)$ \\
\hline \multicolumn{6}{|l|}{ Lower lip } \\
\hline$N$ & 20 & 20 & 15 & 12 & 11 \\
\hline Cl. Speed & $37.02(2.93)$ & $52.39(4.62)$ & $57.83(6.37)$ & $76.97(9.53)$ & $67.69(8.24)$ \\
\hline Op. Speed & $36.30(2.52)$ & $45.98(4.81)$ & $52.16(7.05)$ & $58.89(8.91)$ & $52.28(7.38)$ \\
\hline R.O.M. & $7.74(.61)$ & $8.73(.71)$ & $8.75(.71)$ & $11.07(1.03)$ & $10.21(.95)$ \\
\hline \multicolumn{6}{|l|}{ Upper lip } \\
\hline$N$ & 21 & 21 & 18 & 20 & 16 \\
\hline Cl. Speed & $12.53(.77)$ & $12.40(1.20)$ & $13.83(.93)$ & $15.57(1.45)$ & $15.56(.94)$ \\
\hline Op. Speed & $15.39(.96)$ & $13.65(1.22)$ & $16.50(1.15)$ & $18.07(1.42)$ & $17.83(1.16)$ \\
\hline R.O.M. & $2.87(.20)$ & $2.51(.21)$ & $2.56(.13)$ & $3.09(.19)$ & $3.42(.22)$ \\
\hline
\end{tabular}


and closing speed of the jaw and the upper lip. Receptive communication was significantly correlated with lower lip opening speed, closing speed, and range of movement.

The age-equivalent scores of the BDI-2 expressive communication subtest were significantly associated with mandibular opening speed, and closing speed but not with range of movement. All of the kinematic variables of the lower lip and upper lip, including opening speed, closing speed, and range of movement were significantly correlated with expressive communication.

Jaw opening and closing speed measures were significantly correlated with the attention and memory subtest of the BDI-2. For the lower lip, opening speed, closing speed, and range of movement were all significantly correlated with the attention and memory subtest. None of the kinematic variables for the upper lip were significantly correlated with attention and memory.

The perception and concepts subtest of the BDI-2 was associated with some of the kinematic variables. The age-equivalent scores of the perception and concepts were significantly correlated with mandibular opening

Table 2. Means and standard deviations of the BDI-2 and CDI subtests at each age level.

\begin{tabular}{|c|c|c|c|c|c|}
\hline & \multicolumn{5}{|l|}{ Age } \\
\hline & 9 months & 12 months & 15 months & 18 months & 21 months \\
\hline \multicolumn{6}{|l|}{ BDI-2 } \\
\hline$N$ & 22 & 22 & 23 & 22 & 20 \\
\hline Rec. Comm. & $6.36(2.89)$ & 11.82 (2.97) & 16.09 (3.72) & 21.55 (4.03) & 25.45 (3.85) \\
\hline Exp. Comm & $8.23(1.63)$ & $12.38(2.01)$ & $16.00(3.32)$ & 20.18 (4.68) & $26.00(5.88)$ \\
\hline Att/Mem & $9.59(2.94)$ & $14.38(3.06)$ & $17.52(2.84)$ & 18.77 (2.31) & $21.45(4.09)$ \\
\hline Per/Conc. & $8.86(1.96)$ & $11.29(2.10)$ & $14.13(3.14)$ & 17.64 (2.75) & $21.85(4.02)$ \\
\hline \multicolumn{6}{|l|}{ CDI } \\
\hline$N$ & 23 & 21 & 20 & 20 & 19 \\
\hline \# Phr Und & $5.04(4.58)$ & $12.30(5.87)$ & 20.60 (4.63) & & \\
\hline \# Wds Und & $14.39(20.00)$ & 51.05 (47.87) & $124.25(76.50)$ & & \\
\hline \# Wds Prod & $1.26(1.86)$ & $6.00(11.15)$ & 27.50 (34.62) & 103.95 (107.74) & $187.00(125.86)$ \\
\hline \# Gest Prod & $8.36(6.35)$ & $21.29(8.12)$ & 35.85 (10.03) & & \\
\hline
\end{tabular}

Table 3. Correlations between kinematic variables and sex.

\begin{tabular}{ll}
\hline Variable & Sex \\
\hline Jaw Opening Speed & $.28^{*}$ \\
Jaw Closing Speed & $.32^{* *}$ \\
Jaw R.O.M. & $.24^{*}$ \\
LL Opening Speed & $.34^{*}$ \\
LL Closing Speed & $.31^{*}$ \\
LL R.O.M. & $.34^{*}$ \\
UL Opening Speed & .14 \\
UL Closing Speed & $.24^{*}$ \\
UL R.O.M. & .17 \\
\hline
\end{tabular}

$\mathrm{LL}=$ lower lip, UL = upper lip, R.O.M. = range of movement.

Positive correlations associated with higher values for female participants.

$* p<.05$

${ }^{* *} p<.001$

Table 4. Correlations between kinematic variables and age-equivalent scores of BDI-2 subtests.

\begin{tabular}{lllll}
\hline Variable & $\begin{array}{l}\text { Receptive } \\
\text { communication }\end{array}$ & $\begin{array}{l}\text { Expressive } \\
\text { communication }\end{array}$ & $\begin{array}{l}\text { Attention } \\
\text { and memory }\end{array}$ & $\begin{array}{l}\text { Perception } \\
\text { and concepts }\end{array}$ \\
\hline Sex & .09 & $.20^{*}$ & $.21^{*}$ & .11 \\
Jaw Opening Speed & $.29^{*}$ & $.30^{*}$ & $.30^{*}$ & $.34^{* *}$ \\
Jaw Closing Speed & $.37^{* *}$ & $.36^{* *}$ & $.39^{* *}$ & .19 \\
Jaw R.O.M. & .10 & .13 & .11 & $.28^{*}$ \\
LL Opening Speed & $.31^{*}$ & $.30^{*}$ & $.29^{*}$ & $.41^{* *}$ \\
LL Closing Speed & $.51^{* *}$ & $.54^{* *}$ & $.45^{* *}$ & $.37^{*}$ \\
LL R.O.M. & $.35^{*}$ & $.41^{* *}$ & $.26^{*}$ & .15 \\
UL Opening Speed & $.24^{*}$ & $.24^{*}$ & .13 & .19 \\
UL Closing Speed & $.24^{*}$ & $.22^{*}$ & .17 & .18 \\
UL R.O.M. & .18 & $.21^{*}$ & .05 &
\end{tabular}

$\mathrm{LL}=$ lower lip, UL = upper lip, R.O.M. = range of movement.

Positive correlations associated with higher values for female participants.

$* p<.05$

$* * p<.001$ 
speed and closing speed. All of the lower lip kinematic variables were significantly correlated with perception and memory; however, none of the upper lip kinematic variables were significantly correlated with the attention and memory subtest.

Sex was positively correlated with expressive communication and attention and memory subtests. Specifically, female children had higher expressive communication and attention and memory scores than the male children.

Partial correlations, controlling for the effect of age, between sex, the kinematic, BDI-2, and the CDI variables were also calculated. Aside from a positive correlation $(r=.32, p=.04)$ with upper lip opening speed, sex was not shown to be correlated with any of the variables. To reduce collinearity, sex was removed from the calculation of partial correlations between the kinematic, BDI-2, and CDI variables. The partial correlations, with sex removed as a variable, between the kinematic variables and the BDI-2 are shown in Table 5. Receptive communication was partially correlated with lower lip closing speed and range of movement. Expressive communication was only significantly correlated with lower lip closing speed after controlling for the effect of age. Attention and memory were significantly partially correlated with mandibular closing speed, and significantly negatively correlated with upper lip range of movement. Finally, the perception and concepts subtest was found to have a significant association with jaw opening speed and range of movement.

\subsection{CDI scores}

Table 6 presents the correlations between each kinematic variable, sex, and results from the number of phrases understood (Words and Gestures form), number of word understood (Words and Gestures form), number of words produced (Words and Gestures and Words and Sentences forms), and total number of gestures produced (Words and Gestures form) from the CDI.

The number of phrases understood correlated with jaw and lower lip opening and closing speeds, and lower lip range of movement. The number of words understood was positively correlated only with lower lip kinematic variables, including opening and closing speeds and range of movement. The number of words produced was significantly correlated with jaw and lower lip opening speeds, closing speeds, and ranges of movement. For the upper lip, only the correlation between maximum velocity and number of words was significant $(r=.21, p=.047)$.

The number of gestures produced was significantly correlated with mandibular opening and closing speeds. The number of gestures was significantly correlated with lower lip opening speed, closing speed, and range of movement. Significant correlations of number of words were found with the upper lip closing speed and opening speed.

Finally, sex was shown only to be correlated with the number of words produced. Female participants generally produced more words than the male participants.

Table 5. Partial correlations between kinematic variables and age-equivalent scores of BDI-2 subtests.

\begin{tabular}{lcccc}
\hline Variable & $\begin{array}{l}\text { Receptive } \\
\text { communication }\end{array}$ & $\begin{array}{l}\text { Expressive } \\
\text { communication }\end{array}$ & $\begin{array}{l}\text { Attention } \\
\text { and memory }\end{array}$ & $\begin{array}{l}\text { Perception } \\
\text { and concepts }\end{array}$ \\
\hline Jaw Opening Speed & .12 & .15 & .15 & $.22^{*}$ \\
Jaw Closing Speed & .19 & .17 & $.24^{*}$ & .16 \\
Jaw R.O.M. & .06 & .12 & .06 & $.23^{*}$ \\
LL Opening Speed & .21 & .16 & .15 & .12 \\
LL Closing Speed & $.28^{*}$ & $.29^{*}$ & .14 & .02 \\
LL R.O.M. & $.24^{*}$ & .32 & .04 & .21 \\
UL Closing Speed & -.03 & -.02 & .04 & .04 \\
UL Opening Speed & .10 & .09 & -.07 & -.07 \\
UL R.O.M. & -.07 & .02 & $-.22^{*}$ & -.04 \\
\hline
\end{tabular}

$\mathrm{LL}=$ lower lip, UL = upper lip, R.O.M. = range of movement.

${ }^{*} p<.05 ;{ }^{* *} p<.001$.

Table 6. Correlations between kinematic variables and scores of CDI subtests.

\begin{tabular}{lcccc}
\hline Variable & $\begin{array}{c}\text { \# Phrases } \\
\text { understood }\end{array}$ & $\begin{array}{l}\text { \# Words } \\
\text { understood }\end{array}$ & $\begin{array}{l}\text { \# Words } \\
\text { produced }\end{array}$ & $\begin{array}{c}\text { \# Gestures } \\
\text { produced }\end{array}$ \\
\hline Sex & .001 & .07 & $.22^{*}$ & .10 \\
Jaw Opening Speed & $.31^{*}$ & .16 & $.42^{* *}$ & $.30^{*}$ \\
Jaw Closing Speed & $.33^{*}$ & $.27^{*}$ & $.41^{* *}$ & $.38^{*}$ \\
Jaw R.O.M. & .10 & .03 & $.26^{*}$ & .16 \\
LL Opening Speed & $.54^{* *}$ & $.47^{* *}$ & $.29^{*}$ & $.58^{* *}$ \\
LL Closing Speed & $.46^{* *}$ & $.46^{* *}$ & $.46^{* *}$ & $.45^{*}$ \\
LL R.O.M. & $.31^{*}$ & $.30^{*}$ & $.33^{*}$ & $.32^{*}$ \\
UL Opening Speed & .16 & .25 & $.25^{*}$ & $.29^{*}$ \\
UL Closing Speed & .16 & .22 & $.23^{*}$ & .11 \\
UL R.O.M. & .004 & .04 & $.23^{*}$ & \\
\hline
\end{tabular}

$\mathrm{LL}=$ lower lip, $\mathrm{UL}=$ upper lip, R.O.M. = range of movement. Positive correlations associated with higher values for female participants. ${ }^{*} p<.05 ;{ }^{* *} p<.001$ 
To control for the effect of age, partial correlations were also conducted as described above. The partial correlations, with sex removed as a variable, between the kinematic measures and the CDI scores are presented in Table 7. The number of phrases understood and the number of words understood were significantly correlated with lower lip opening speed after controlling for the effect of age. The number of words produced had significant partial correlations with the jaw closing speed, and the upper lip opening and closing speeds. The number of gestures was significantly correlated with all the lower and upper lip kinematic variables after controlling for the effect of age.

\section{Discussion}

In this longitudinal study, developmental changes in orofacial movement speeds were correlated with developmental gains in language and cognitive skill; some of these correlations remained even after the variables were controlled for age. Because the current findings were only based on correlation analyses, future work is required to identify the causal relations among changes across domains. Although speculative, several plausible mechanisms could account for the observed association between the development of articulatory movement speeds and cognitive and language skills. The observed associations are consistent with theories of communicative development that posit across domain interactions (Smith and Goffman, 2004; Thelen, 1995) and potentially shared underlying processes (Thal, 1991).

\subsection{Sex effects}

Sex was correlated with some of the CDI, BDI-2, and kinematic variables. Specifically, the total number of words differed between male and female participants in the CDI, similar to previous findings (Bavin et al., 2008; Dale et al., 1989). Previous studies have also identified sex differences in kinematic variables at some ages. For instance, between 4 and 5 years of age, boys exhibit greater variability than girls in the vertical opening of the lips during speech (Smith \& Zelaznik, 2004). However in the present study, the associations between sex and all variables, except for upper lip opening speed, were no longer present after age was controlled for.

\subsection{Shared underlying processes}

One potential reason for the association between kinematic measures and cognitive and language test scores is that these skills rely on the same underlying processes. Researchers have proposed that gestures are correlated with specific cognitive skills at specific points in development because both tap into the same underlying processes (Thal, 1991). In the current study, the increased memory sub-test of the BDI-2 was associated with faster jaw speeds and smaller upper lip range of movement, even controlling for age. Working memory has been proposed as an underlying process that allows a child to make gains in language and gesture (Thal, 1991). Specifically, the phonological loop of working memory may assist in maintaining auditory input and planning speech movements for novel words (Dollaghan and Campbell, 1998; Gathercole and Baddeley, 1990). Gains in working memory capacity may allow for more efficient speech motor planning thereby affecting the speed at which phonemes in babbling and words are produced, resulting in faster movement speeds and smaller ranges of movements.

\subsection{Embodied cognition}

Several of the current observations are consistent with predictions made by the theory of embodied cognition. This theory posits that cognitive concepts are developed due to the constraints of our physical bodies, environment, and sensorimotor skills (Iverson and Thelen, 1999; Thelen et al., 2001). Infants' actions are considered vital in shaping abstract, cognitive concepts (Thelen, 1995; von Hofsten, 2007). Infants are born with an awareness of their bodies due to prenatal spontaneous movements and this awareness of their physical capabilities may explain some of in-

Table 7. Partial correlations between kinematic variables and scores of CDI subtests.

\begin{tabular}{lcccc}
\hline Variable & $\begin{array}{c}\text { \# Phrases } \\
\text { understood }\end{array}$ & $\begin{array}{c}\text { \# Words } \\
\text { understood }\end{array}$ & $\begin{array}{c}\text { \# Words } \\
\text { produced }\end{array}$ & $\begin{array}{c}\text { \# Gestures } \\
\text { produced }\end{array}$ \\
\hline Jaw Opening Speed & .08 & -.07 & .12 & .07 \\
Jaw Closing Speed & .02 & .00 & .17 & .09 \\
Jaw R.O.M. & .03 & -.09 & .07 & .15 \\
LL Opening Speed & $.41^{*}$ & $.32^{*}$ & .18 & $.42^{*}$ \\
LL Closing Speed & .19 & .21 & .10 & $.38^{*}$ \\
LL R.O.M. & .23 & .21 & .12 & .25 \\
UL Closing Speed & .08 & .06 & .19 & $.37^{*}$ \\
UL Opening Speed & .14 & .14 & .18 & $.38^{*}$ \\
UL R.O.M. & .21 & .11 & &
\end{tabular}

$\mathrm{LL}=$ lower lip, $\mathrm{UL}=$ upper lip, R.O.M. = range of movement.

${ }^{*} p<.05 ;{ }^{* *} p<.001$ 
fants' early skills (Gallagher, 2005; Green and Wilson, 2006). For instance, Gallagher (2005) suggests that neonates' prenatal spontaneous movements of their facial structures provide them with an understanding of the capacity of facial movements by the time they are born. Gallagher (2005) argues that this understanding is the reason neonates are visually biased to human faces. The resulting awareness of their capacities and the bias to faces is what allows neonates to perceive and consequently imitate facial expressions moments after birth (Gallagher, 2005).

Conceivably, infants with more experience with their bodies through spontaneous motility, and thereby a greater understanding of their physical capacities and capabilities, may have a greater understanding of the world around them. The association seen in this study between faster jaw opening speeds and the perception and concepts subtest may reflect the role of embodied cognition in development. Speech movement speeds generally increase with age (Nip and Green, 2006; Smith and Zelaznik, 2004) and faster articulatory speeds may indicate a more mature speech motor system and greater experience with the physical body. This increased awareness of the body, including the articulators, may allow an infant to more readily acquire cognitive concepts that form the basis of early communication.

\subsection{Bidirectional relations between speech motor and language skills}

The associations found between cognition, language, and speech motor performance are consistent with the results of previous studies demonstrating the variable influences of cognitive and linguistic processing demands on speech motor planning and programming. For example, the variability of speech movement patterns has been observed to increase as utterances become increasingly more complex linguistically (Dromey and Bates, 2005; Kleinow and Smith, 2006; Maner et al., 2000). The variability of speech movement patterns also increases during the performance of a concurrent cognitive task, such as mental arithmetic (Dromey \& Benson, 2003). In addition, task demands have been shown to influence articulatory movement speed in older children and adults (Nip \& Green, 2006) and during early speech development (Nip, Green, \& Marx, 2009). For instance, articulatory movements produced during words or babbling are significantly faster than during silent spontaneous movements (Nip et al., 2009). Additional studies are needed to better understand the influence of cognition and language formulation on the development of early speech motor performance and whether these relations change as children become older.

Models of communication development also need to consider the influence of speech motor development on phonologic and expressive language development. Green et al. (2002) found that during the first 2 years of life, lower lip movements were not independent of the jaw. This potential constraint on independent lower lip movement may explain why labiodental fricatives tend to not appear earlier than 2 years of age (Green et al., 2002). The constraints on speech motor skills may be one limiting factor affecting the acquisition of speech sounds. A toddler's phonetic repertoire may, in turn, limit the rate of new word acquisition as toddlers tend to produce words that contain sounds in their existing phonetic repertoire (de Boysson-Bardies et al., 1984; Locke, 1989; Oller et al., 1976; Stoel-Gammon, 1985; Vihman, 1986). This relation between phonetic repertoire and lexicon size may account for the current finding that the number of words and the number of gestures is positively correlated with every kinematic variable in the current study. A larger phonetic inventory may result not only in more possible words a child can produce but also more mature speech movement, such as increased range of movement and faster speed (Nip et al., 2009).

Recently, Green and Nip (2010) proposed a conceptual framework for examining the interaction between the development of speech motor control and other domains. They broadly characterized the factors that influence the developmental course of speech as either catalysts or functional constraints. Catalysts are factors that ultimately accelerate speech development and functional constraints are factors that limit speech motor control in early development (Green \& Nip, 2010). Catalysts to speech motor development represent factors that pressure the speech system to adapt to newly emerging communication demands. Conceivably, the observed correlations between articulatory speed, cognitive, and language skills may reflect the catalyzing effects of emerging demands imposed by increasing cognitive and linguistic abilities (i.e., production of longer and more complex utterances and acquisition of new words) on emergent speech motor skills. Support for this assertion is provided by a recent finding that the speed of lip and jaw movements increase from 9 to 15 months, when children are beginning to use first words (Nip et al., 2009). The association of cognition, language, and articulatory speed appears to be present throughout development. Speaking tasks involving greater cognitive and linguistic processing needs are associated with faster articulatory speeds in children and adults (Nip \& Green, 2006). Further understanding of how different skills and domains may act as catalysts or functional constraints during speech development is essential for advancing theories of speech and language development and for improving the early identification of children at risk of speech delays at earlier ages.

\subsection{Conclusions}

This exploratory study identified relations between kinematic variables and standardized measure of language and cognitive skills. Of course, additional work is needed to determine the causal relations and to explore potential implications for understanding the mechanisms underlying communication impairments. The current investigation used subtests from the BDI-2, a tool that is meant to provide a global snapshot of a child's development. In the future, more sensitive measures of language and cognitive skills should be used to determine the relations between specific aspects of language and cognition with movement characteristics. Future work is also needed to identify which specific skills, such as attention, working memory, syntactic skills, and language comprehension, act as a catalyst or functional constraint on speech motor development. In addition, longitudinal studies utilizing structural equation 
modeling or multilevel modeling are needed across a longer period of development to determine if the strength and direction of the observed relations remain static across development or change at varying points of development. Eventually, a better understanding of the relations of cognition, language, and speech motor development may allow for earlier identification of children at risk of developing later speech and language delays.

Acknowledgments - This work has been supported by the National Institute of Health, National Institute on Deafness and Other Communication Disorders (R01DC006463) and the Natural Sciences and Engineering Research Council of Canada (PGS D2-331510-2006). The authors would like to thank Cynthia Didion, Lindsey Fairchild, Kimber Green, Lauren Head, Megan Kleensang, Lacey LaBarge, Laura Maack, Antje Mefferd, Cory Quinlan, Kelly Raber, Paige Mueller, Cara Ullman, and Kara Weaver and for their assistance with data collection and analysis. The authors would also like to thank David R. Beukelman and Thomas D. Carrell for their comments on earlier drafts of this article.

\section{Appendix A. Continuing education}

\section{CEU Questions}

1. Speech development is thought to depend on:
a. affect
b. cognition
c. language
d. speech motor control
e. all of the above

2. Speech movement data was collected using:
a. electromyography
b. optical motion capture
c. electromagnetic articulography
d. video coding

3. Articulatory movement speed was not found to be associated with increases in cognitive or language skills.
a. True
b. False

4. The authors suggest that models of communication development may need to:

a. account for speech motor development, especially when considering phonology and expressive language development

b. ignore the influence of speech motor development on communication development

c. focus primarily on phonology and expressive language

d. focus only speech motor development

5. Using the Green and Nip (2010) framework, the authors suggest that the association in articulatory speed, cognition, and language measures are an example of:

a. functional constraint

b. shared underlying process

c. embodied cognition

d. catalyst

\section{References}

Acredolo and Goodwyn, 1988 • L. Acredolo and S. Goodwyn, Symbolic gesturing in normal infants, Child Development 59 (1988), pp. $450-466$.

Alcock, 2006 - K. Alcock, The development of oral motor control and language, Down Syndrome Research and Practice 10 (2006).

Bavin et al., 2008 - L. E. Bavin, M. Prior, S. Reilly, L. Bretherton, J. Williams, P. Eadie, et al., The early language in Victoria study: Predictive vocabulary at age one and two years from gesture and object use, Journal of Child Language 35 (2008), pp. 687-701.

Carson et al., 2003 • C. P. Carson, T. Klee, D. K. Carson, and L. K. Hime, Phonological profiles of 2-year-olds with delayed language development: Predicting clinical outcomes at age 3, American Journal of Speech-Language Pathology 12 (2003), pp. $28-39$.

Dale et al., 1989 - P. S. Dale, E. Bates, J. S. Reznick, and C. Morisset, The validity of parent report instrument of child language at twenty months, Journal of Child Language 16 (1989), pp. 239-249.

de Boysson-Bardies et al., 1984 - B. de Boysson-Bardies, L. Sagart, and C. Durand, Discernible differences in the babbling of infants according to target language, Journal of Child Language 11 (1984), pp. 1-15.

Dollaghan and Campbell, 1998 - C. A. Dollaghan and T. F. Campbell, Nonword repetition and child language impairment, Journal of Speech, Language and Hearing Research 41 (1998), pp. 1136-1146.

Dromey and Bates, 2005 - C. Dromey and E. Bates, Speech interactions with linguistic, cognitive, and visuomotor tasks, Journal of Speech, Language, and Hearing Research 48 (2005), pp. 295-305.

Dromey and Benson, 2003 - C. Dromey and A. Benson, Effects of concurrent motor, linguistic, or cognitive tasks on speech motor performance, Journal of Speech, Language and Hearing Research 46 (2003), pp. 1234-1246.

Fenson and Ramsay, 1980 - L. Fenson and D. S. Ramsay, Decentration and integration of the child's play in the second year, Child Development 51 (1980), pp. 171-178.

Fenson et al., 1993 • L. Fenson, P. S. Dale, J. S. Reznick, D. Thal, E. Bates, J. P. Hartung, et al., The MacArthur Communicative Development Inventories: User's guide and technical manual (2nd ed.), Singular Publishing Group, San Diego, CA (1993).

Gallagher, 2005 - S. Gallagher, How the body shapes the mind, Oxford University Press, Oxford, UK (2005). 
Gathercole and Baddeley, 1990 - S. E. Gathercole and A. D. Baddeley, The role of phonological memory in vocabuloary acquisition: A study of young children learning new names, British Journal of Psychology 81 (1990), pp. 439-454.

Goffman and Smith, 1999 • L. Goffman and A. Smith, Development and phonetic differentiation of speech movement patterns, Journal of Experimental Psychology: Human Perception and Performance 25 (1999), pp. 649-660.

Goffman, 1999 • L. Goffman, Prosodic influences on speech production in children with specific language impairment and speech deficits: Kinematic, acoustic, and transcription evidence, Journal of Speech, Language, and Hearing Research 42 (6) (1999), pp. 1499-1517.

Goldin-Meadow and Butcher, 2003 - S. Goldin-Meadow and C. Butcher, Pointing: Where language, culture, and cognition meet. In: S. Kita, Editor, Pointing Toward Two Word Speech in Young Children, Lawrence Erlbaum Associates, Hillsdale, NJ (2003), pp. 85-107.

Green and Nip, 2010 - J. R. Green and I. S. B. Nip, Some organization principles in early speech development. In: B. Maaseen and P. H. H. M. van Lieshout, Editors, Speech motor control: New developments in basic and applied research, Oxford University Press, NC (2010), pp. 171-188.

Green and Wilson, 2006 - J. R. Green and E. M. Wilson, Spontaneous facial motility in infancy: A 3D kinematic analysis, Developmental Psychobiology 48 (2006), pp. 16-28

Green et al., 2000 - J. R. Green, C. A. Moore, M. Higashikawa, and R. W. Steeve, The physiological development of speech motor control: Lip and jaw coordination, Journal of Speech, Language and Hearing Research 43 (2000), pp. 239-255.

Green et al., 2002 • J. R. Green, C. A. Moore, and K. J. Reilly, The sequential development of jaw and lip control for speech, Journal of Speech, Language and Hearing Research 45 (2002), pp. 66-79.

Green et al., 2007 • J. R. Green, E. M. Wilson, Y. T. Wang, and C. A. Moore, Estimating mandibular motion based on chin surface targets during speech, Journal of Speech, Language and Hearing Research 50 (2007), pp. 928-939.

Iverson and Thelen, 1999 • J. M. Iverson and E. Thelen, Hand, mouth, and brain: The dynamic emergence of speech and gesture, Journal of Consciousness Studies 6 (1999), pp. 19-40.

Iverson et al., 2008 J. M. Iverson, O. Capirci, V. Volterra, and S. Goldin-Meadow, Learning to talk in a gesture-rich world: Early communication in Italian vs. American children, First Language 28 (2008), pp. 164-181.

Kleinow and Smith, 2006 - J. Kleinow and A. Smith, Potential interactions among linguistic, autonomic, and motor factors in speech, Developmental Psychobiology 48 (2006), pp. 275-287.

Levelt, 1989 - W. J. M. Levelt, Speaking: From intention to articulation, MIT, Cambridge, MA (1989).

Locke, 1989 • J. L. Locke, Babbling and early speech: Continuity and individual differences, First Language 9 (1989), pp. 191-206.

Maner et al., 2000 - K. J. Maner, A. Smith, and L. Grayson, Influences of utterance length and complexity on speech motor performance in children and adults, Journal of Speech, Language, and Hearing Research 43 (2000), pp. 560-573.

Newborg, $2005 \bullet J$. Newborg, Battelle Developmental Inventory (2nd ed.), Riverside Publishing, Itasca, IL (2005).

Nip and Green, 2006 - I. S. B. Nip and J. R. Green, The development of speaking rate: A kinematic perspective, Paper presented at the conference on motor speech, Austin, TX (2006).

Nip et al., 2009 - I. S. B. Nip, J. R. Green and D. B. Marx, Early speech motor development: Cognitive and linguistic considerations, Journal of Communication Disorders 42 (2009), pp. 286-298.

Oller et al., 1976 • D. K. Oller, L. Wieman, W. Doyle and C. Ross, Infant babbling and speech, Journal of Child Language 3 (1976), pp. 1-11.

Özçaliskan and Goldin-Meadow, 2005 • S. Özçaliskan and S. Goldin-Meadow, Gesture is at the cutting edge of early language development, Cognition 96 (2005), pp. B101-B113.

Paul and Jennings, 1992 - R. Paul and P. Jennings, Phonological behavior in toddlers with slow expressive language development, Journal of Speech and Hearing Research 35 (1992), pp. 99-107.

Powell and Bishop, 1992 - R. P. Powell and D. V. M. Bishop, Clumsiness and perceptual problems in children with specific language impairment, Developmental Medicine and Child Neurology 34 (1992), pp. 755-765.

Rescorla and Ratner, 1996 - L. Rescorla and N. B. Ratner, Phonetic profiles of toddlers with specific expressive language impairment (SLI-E), Journal of Speech and Hearing Research 39 (1996), pp. 153-165.

Smith and Gartenburg, 1984 - B. L. Smith and T. E. Gartenburg, Initial observations concerning developmental characteristics of labio-mandibular kinematics, Journal of the Acoustic Society of America 75 (1984), pp. 1599-1605.

Smith and Goffman, 2004 - A. Smith and L. Goffman, Interaction of language and motor factors in speech production. In: B. Maasen, R. D. Kent, H. F. M. Peters, P. H. H. M. van Lieshout and W. Hulstijn, Editors, Speech Motor Control in Normal and Disordered Speech, Oxford University Press, Oxford (2004), pp. 225-252.

Smith and Zelaznik, 2004 - A. Smith and H. N. Zelaznik, Development of functional synergies for speech motor coordination in childhood and adolescence, Developmental Psychobiology 45 (2004), pp. 22-33.

Smith et al., 2006 • B. L. Smith, K. K. McGregor and D. Demille, Phonological development in lexically precocious 2-year-olds, Applied Psycholinguistics 27 (2006), pp. 355-375

Stark and Blackwell, 1997 - R. E. Stark and P. B. Blackwell, Oral volitional movements in children with language impairments, Child Neuropsychology 3 (1997), pp. 81-97.

Stark and Tallal, 1981 - R. E. Stark and P. Tallal, Perceptual and motor deficits in language impaired children. In: R. W. Keith, Editor, Central Auditory and Language Disorders in Children, College-Hill Press, San Diego (1981), pp. 121-144.

Stoel-Gammon, 1985 - C. Stoel-Gammon, Phonetic inventories, 15-24 months: A longitudinal study, Journal of Speech and Hearing Research 28 (1985), pp. 505-512.

Stoel-Gammon, 1991 • C. Stoel-Gammon, Normal and disordered phonology in two year-olds, Topics in Language Disorders 11 (1991), pp. $21-32$.

Thal, 1991 - D. Thal, Language and cognition in normal and late-talking toddlers, Topics in Language Disorders 11 (1991), pp. 33-42.

Thal and Tobias, 1992 - D. Thal and S. Tobias, Communicative gestures in children with delayed onset of oral expressive vocabulary, Journal of Speech and Hearing Research 35 (1992), pp. 1281-1289.

Thal and Tobias, 1994 - D. Thal and S. Tobias, Relationships between language and gesture in normally developing and late-talking toddlers, Journal of Speech and Hearing Research 37 (1994), pp. 157-170.

Thelen, 1995 - E. Thelen, Time-scale dynamics and the development of an embodied cognition. In: R. F. Port and T. van Gelder, Editors, Mind as motion: Explorations in the dynamics of cognition, MIT Press, Cambridge, MA (1995), pp. 69-100.

Thelen, 2001 • E. Thelen, Dynamic mechanisms of change in early perceptual-motor development. In: J. L. McClelland and R. S. Siegler, Editors, Mechanisms of cognitive development: Behavioral and neural perspectives, Lawrence Erlbaum Associates, Mahwah, NJ (2001), pp. 161-184.

Thelen et al., 2001 - E. Thelen, G. Schöner, C. Scheier, and L. B. Smith, The dynamics of embodiment: A field theory of infant perseverative reaching, Behavioral and Brain Sciences 24 (2001), pp. 1-86.

Ungerer and Sigman, $1984 \cdot$ J. A. Ungerer and M. Sigman, The relation of play and sensorimotor behavior to language in the second year, Child Development 55 (1984), pp. 1448-1455.

Vihman, 1986 - M. M. Vihman, Individual differences in babbling and early speech: Predicting to age three. In: B. Lindblom and R. Zetterstrom, Editors, Precursors of early speech Vol. 44, Stockton Press, New York (1986), pp. 95-109.

Vihman and Greenlee, 1987 • M. M. Vihman and M. Greenlee, Individual differences in phonological development: Ages one and three years, Journal of Speech and Hearing Research 30 (1987), pp. 503-521.

von Hofsten, 2007 C. von Hofsten, Action in development, Developmental Science 10 (2007), pp. 54-60.

Walsh and Smith, 2002 • B. Walsh and A. Smith, Articulatory movements in adolescents: Evidence for protracted development of speech motor control processes, Journal of Speech, Language, and Hearing Research 45 (2002), pp. 1119-1133.

Whitehurst et al., 1991 - G. J. Whitehurst, M. Smith, J. E. Fischel, D. S. Arnold, and C. J. Lonigan, The continuity of babble and speech in children with specific expressive language delay, Journal of Speech and Hearing Research 34 (1991), pp. 1121-1129.

Williams and Elbert, 2003 - A. L. Williams and M. Elbert, A prospective longitudinal study of phonological development in late talkers, Language, Speech, and Hearing Services in Schools 34 (2003), pp. 138-153. 